\title{
Article
}

\section{There is still a case for a generic qualitative approach in some pharmacy practice research}

\author{
Auta, Asa, Strickland-Hodge, Barry and Maz, Juila \\ Available at http://clok.uclan.ac.uk/15002/ \\ Auta, Asa ORCID: 0000-0001-6515-5802, Strickland-Hodge, Barry and Maz, \\ Juila (2017) There is still a case for a generic qualitative approach in some \\ pharmacy practice research. Research in Social and Administrative Pharmacy, \\ 13 (1). pp. 266-268. ISSN 1551-7411
}

It is advisable to refer to the publisher's version if you intend to cite from the work. http://doi.org/10.1016/j.sapharm.2016.06.005

For more information about UCLan's research in this area go to http://www.uclan.ac.uk/researchgroups/ and search for < name of research Group>.

For information about Research generally at UCLan please go to http://www.uclan.ac.uk/research/

All outputs in CLoK are protected by Intellectual Property Rights law, including Copyright law. Copyright, IPR and Moral Rights for the works on this site are retained by the individual authors and/or other copyright owners. Terms and conditions for use of this material are defined in the policies page.

\section{CLoK}

Central Lancashire online Knowledge www.clok.uclan.ac.uk

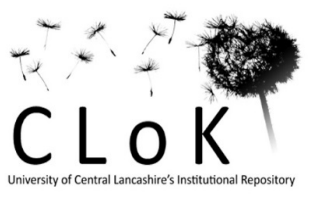


There is still a case for a generic qualitative approach in some pharmacy practice research

Asa Auta ${ }^{1}, \mathrm{PhD}$

${ }^{1}$ Lecturer, School of Pharmacy and Biomedical Sciences, University of Central Lancashire, Preston, PR1 2HE, UK

Barry Strickland-Hodge ${ }^{2,3}, \mathrm{PhD}$

${ }^{2}$ Principal Teaching Fellow, School of Healthcare, Faculty of Medicine and Health, University of Leeds, Leeds, LS2 9JT, UK.

${ }^{3}$ Visiting Professor of Pharmacy Practice and Policy, Centre for Technology Enabled Health Research, Faculty of Health and Life Sciences, Coventry University, Coventry, CV1 5FB, UK

Julia $\mathrm{Maz}^{2}, \mathrm{PhD}$

${ }^{2}$ Lecturer, School of Healthcare, Faculty of Medicine and Health, University of Leeds, Leeds, LS2 9JT, UK.

Corresponding author: Asa Auta, School of Pharmacy and Biomedical Sciences, University of Central Lancashire, Preston, PR1 2HE, UK. Email: aauta@uclan.ac.uk 


\section{There is still a case for a generic qualitative approach in some pharmacy practice research}

Pharmacy practice researchers are increasingly employing qualitative research to understand complex social problems. ${ }^{1}$ This is as a result of the value of qualitative research in exploring people's experience, behaviour and emotions, and in understanding a phenomenon from the participants' perspectives.

Qualitative research involves a wide range of philosophies and approaches and has been variously classified and described in the literature. Creswell identified five approaches to qualitative inquiry namely the narrative, phenomenology, grounded theory, ethnography and case study. ${ }^{2}$ However, a number of other approaches exist including autoethnography, participatory action research and conversational analysis. ${ }^{2,3}$ These conventional approaches are increasingly employed in healthcare research including pharmacy practice research and sometimes researchers feel obligated to adopt these approaches in their qualitative studies. ${ }^{4}$ However, our experience in one of our studies still makes a case for a generic approach in some pharmacy practice research. We therefore present a brief overview of the two qualitative approaches, phenomenology and grounded theory that we thought could be applicable to our research. Alongside, we discussed how for pragmatic reasons we decided to adopt a generic approach in our qualitative study. Our study was conducted to investigate stakeholders' views on the granting of prescribing authority to pharmacists in Nigeria. ${ }^{5}$ The objectives of our study were to explore the views of stakeholders on the facilitators and barriers to making prescribing a part of the clinical roles of pharmacists and to identify the potential changes needed for the development of pharmacist prescribing in Nigeria.

First, we considered phenomenology as an approach. Qualitative researchers generally employed a phenomenological approach to understand the essence of a 'lived experience' of a phenomenon for several individuals. ${ }^{2}$ Therefore, some authors have argued that phenomenology is a philosophical approach that underpins all qualitative research because all qualitative research is conducted to uncover how people make sense of their experience. ${ }^{6}$ Participants in phenomenological studies are individuals who have experienced the phenomenon being investigated. In phenomenological studies, data are primarily collected through interviews. However, other sources of data including observations, poems, and documents have been used. ${ }^{2,6}$

A number of pharmacy practice researchers including Makwosky et al., ${ }^{7}$ have employed a phenomenological approach in their qualitative inquiry. In reference to our Nigerian study, a good research question for a phenomenological study would have been: "what does it mean to be a pharmacist prescriber?" Or "what is the nature of the experience of pharmacist 
prescribing?" However, our Nigerian participants who included policymakers, doctors, pharmacists and patient group representatives have no experience of pharmacist prescribing. Furthermore, phenomenology mostly employs unstructured interviews to allow the study participants to describe the meaning of their experience with a phenomenon. This form of interview is usually driven by the interviewee. Hence, the specific objectives of our study are not likely to be achieved by this approach.

Grounded theory employs an iterative process of data collection and analysis to inductively generate theory for a process or an action through the data collected from participants who have experienced the process. ${ }^{2,8}$ There are at least three different approaches in grounded theory including the Glaser's approach, Strauss and Corbin's approach and constructivist grounded theory. ${ }^{8-11}$ Details of these approaches are beyond the scope of this paper. Despite these different approaches, a key defining feature of grounded theory is the development or discovery of a theory or theories that are grounded in the data. ${ }^{2}$ Hence, a grounded theory design is particularly useful where no theory exists to explain an action or process in a topic area. ${ }^{2,12}$ A number of pharmacy practice researchers including Adigwe et al., ${ }^{13}$ have employed the principles of grounded theory in their qualitative investigations. A grounded theory approach would have been appropriate for our research if the aim was to generate a theory. However, generating a theory was not the explicit aim of our study as a number of theories or models of role expansion and practice change exist and have been used to explain human behaviour towards role expansion in pharmacy. ${ }^{14,15}$ Although a grounded theory approach would help in identifying barriers to pharmacist prescribing by looking at the concerns of stakeholders as they view allowing pharmacists to prescribe, this approach would however, fail to identify potential changes needed (i.e. what can be done?) for the development of pharmacist prescribing in Nigeria. This is because grounded theory is one of sociological action and looks at documented behaviour of study participants; for example, what people do to resolve their concerns rather than what can be done..$^{8,11}$ Since prescribing is not currently implemented in Nigeria, applying a grounded theory approach to answer this research question was considered inappropriate.

In view of the limitations associated with the approaches described above, a generic approach to inquiry was considered appropriate for our qualitative study. A generic qualitative research approach seeks to "discover and understand a phenomenon, a process, or the perspectives and world views of the people involved"16 rather than lay emphasis on philosophical underpinnings. ${ }^{17}$ Generic approaches have also been referred to as qualitative description and interpretative description in the literature. ${ }^{4,12}$ Many qualitative research studies in pharmacy practice including Kamarudin et al., ${ }^{18}$ were not underpinned by any of the established strategies of inquiry. Researchers employ a generic approach in their studies for practical 
reasons such as an inability to find a specific approach that fits the study, making the research aim a priority over a philosophical stance, and a desire to accurately represent participants' views. ${ }^{4,12}$ These practical reasons lie behind the choice of a generic approach in our qualitative study.

\section{Conflict of interest}

The authors do not have any conflict of interest to declare.

\section{References}

1. Smith F. Health services research methods in pharmacy: Qualitative interviews. Int $J$ Pharm Pract 1998;6(2):97-108.

2. Creswell JW. Qualitative inquiry and research design: choosing among five approaches. 3rd ed. 2013, Los Angeles: SAGE Publications, Inc.

3. Denzin, N.K. and Y.S. Lincoln, The discipline and practice of qualitative research, in Strategies of qualitative inquiry, N.K. Denzin and Y.S. Lincoln, Editors. 2008, SAGE Publications: Los Angeles.

4. Sandelowski M. Focus on research methods: whatever happened to qualitative description? Research in Nursing \& Health 2000. 23:334-340.

5. Auta A, Strickland-Hodge B, Maz J. Stakeholders' views on granting prescribing authority to pharmacists in Nigeria: a qualitative study. Int J Clin Pharm 2016; DOI:10.1007/s11096-016-0321-6.

6. Hourigan RM, Edgar SN. Phenomenological research in music education. In the Oxford handbook of qualitative research in American music education, C.M. Conway, Editor. 2014, Oxford University Press: Oxford.

7. Makwosky MJ, Schindel TJ, Rosenthal M, Campbell K, Tsuyuki RT, Madill HM. Collaboration between pharmacists, physicians and nurse practitioners: a qualitative investigation of working relationships in the inpatient medical setting. $J$ Interprof Care 2009 Mar;23(2):169-84.

8. Strauss A, Corbin J. Basics of qualitative research: techniques and procedures for developing grounded theory. 2nd ed. 1998, Thousand Oaks: SAGE Publications, Inc.

9. Mills J, Bonner A, Francis K. The development of constructivist grounded theory. International Journal of Qualitative Methods 2008;5(1):25-35.

10. Charmaz K. Constructing grounded theory: a practical guide through qualitative analysis. 2006, London: Sage.

11. Glaser BG, Strauss AL. The discovery of grounded theory: strategies for qualitative research. 1967, New York: Aldine Publishing Company. 
12. Cooper S, Endacott R. Generic qualitative research: a design for qualitative research in emergency care? Emerg Med J 2007;24:816-819.

13. Adigwe OP, Strickland-Hodge P, Briggs M, Closs SJ. Developing a grounded theory to understand non-medical prescribing for chronic pain. Int $J$ Pharm Pract 2013;21(S1):21.

14. Roberts AS, Hopp T, Sørensen EW, Benrimoj SI, Chen TF, Herborg H. Understanding practice change in community pharmacy: a qualitative research instrument based on organisational theory. Pharm World Sci. 2003;25(5):227-34.

15. Adamcik BA, Ransford HE, Oppenheimer PR, Brown JF, Eagan PA, Weissman FG. New clinical roles for pharmacists: a study of role expansion. Soc Sci Med. 1986;23(11):1187-200.

16. Merriam, S.B., Qualitative research and case study applications in education. 1998, San Francisco: John Wiley \& Sons.

17. Caelli K, Ray L, Mill J. 'Clear as mud': toward greater clarity in generic qualitative research. International Journal of Qualitative Methods 2003;2(2):1-24.

18. Kamarudin G, Penm J, Chaar B, Moles R. Preparing hospital pharmacists to prescribe: stakeholders' views of postgraduate courses. Int J Pharm Pract. 2013;21(4):243-51. 